\title{
Income, Health and Wellbeing Around the World: Evidence from the Gallup World Poll
}

\author{
Angus Deaton \\ Angus Deaton is Dwight D. Eisenhower Professor of International Affairs at the Woodrow Wilson \\ School of Public and International Affairs and Professor of Economics and International Affairs, both \\ at Princeton University, Princeton, New Jersey. He is also a Research Associate, National Bureau \\ of Economic Research, Cambridge, Massachusetts. His e-mail address is \\ $<$ deaton@princeton.edu>
}

\begin{abstract}
During 2006, the Gallup Organization conducted a World Poll that used an identical questionnaire for national samples of adults from 132 countries. I analyze the data on life satisfaction and on health satisfaction and look at their relationships with national income, age, and life-expectancy. Average life satisfaction is strongly related to per capita national income; each doubling of income is associated with a near one point increase in life satisfaction on a scale from 0 to 10 . Unlike most previous findings, the effect holds across the range of international incomes; if anything, it is slightly stronger among rich countries. Conditional on national income, recent economic growth makes people less satisfied with their lives, improvements in life-expectancy make them more satisfied, but life-expectancy itself has little effect. In most countries, except the richest, older people are less satisfied with their lives. National income moderates the effects of aging on self-reported health, and the decline in health satisfaction with age is much stronger in poor countries than in rich countries. In line with earlier findings, people in much of Eastern Europe and in the countries of the former Soviet Union are particularly dissatisfied with their lives and with their health, and older people in those countries are much less satisfied with their lives and with their health than are younger people. HIV prevalence in Africa has little effect on Africans' life or health satisfaction; the fraction of Kenyans who are satisfied with their personal health is the same as the fraction of Britons and higher than the fraction of Americans. The US ranks $88^{\text {th }}$ out of 120 countries in the fraction of people who have confidence in their healthcare system, and has a lower score than countries such as India, Iran, Malawi, Afghanistan or Angola . While the strong relationship between life-satisfaction and income gives some credence to the measures, as do the low levels of life and health satisfaction in Eastern Europe and the countries of the former Soviet Union, the lack of correlations between life and health satisfaction and health measures shows that self-assessed life or health evaluations cannot be regarded as useful summary indicators of human welfare in international comparisons.
\end{abstract}

\section{Keywords}

Gallup World Poll; Happiness; Life-satisfaction; Health; Income; Aging; HIV; Healthcare

The great promise of surveys in which people report their own level of life satisfaction is that such surveys might provide a straightforward and easily-collected measure of individual or national well-being that aggregates over the various components of wellbeing, such as economic status, health, family circumstances, and even human and political rights. Layard (2005) argues forcefully such measures do indeed achieve this end, providing measures of individual and aggregate happiness that should be the only gauges used to evaluate policy and progress. Such a position is in sharp contrast to the more widely accepted view, associated with Sen (1999), which is that human well-being depends on a range of functions and capabilities 
that enable people to lead a good life, each of which needs to be directly and objectively measured and which cannot, in general, be aggregated into a single summary measure.

Which of life's circumstances are important for life satisfaction, and which-if any-have permanent as opposed to merely transitory effects has been the subject of lively debate. For economists, who usually assume that higher incomes represent a gain to the satisfaction of individuals, the role of income is of particular interest. It is often argued that income is both relatively unimportant and relatively transitory compared with family circumstances, unemployment, or health (for example, Easterlin, 2003). Comparing results from a given country over time, Easterlin $(1974,1995)$ famously noted that average national happiness does not increase over long timespans, in spite of large increases in per capita income. These findings suggest little or no long run relationship between a nation's income and its average level life satisfaction. Many studies comparing people within countries have found only a small effect of income on life satisfaction relative to other life-circumstances such as employment or marital status (for example, Helliwell, 2003; Blanchflower and Oswald, 2004). Kahneman et al. (2005) argue that even these measures overstate the effects of income. They suggest that more income may do nothing for experienced happiness, and that the observed correlation between life satisfaction and income comes from a "focusing illusion," which prompts respondents to compare their incomes with some standard set by their own previous incomes or by the incomes of others. It is therefore possible that, over the long run, increases in income will generate no increase in life-satisfaction. This result is consistent with the micro-level evidence from the German Socioeconomic Panel by Di Tella et al. (2005), who regress life satisfaction on income and on several lags of income, and find that life-satisfaction adapts completely to income within four years. In this work, income growth only provides only a temporary boost to life satisfaction.

Given this evidence from individual countries over time and across people within countries, one might reasonably infer that there should be no correlation between levels of life satisfaction across countries at different levels of income. One argument, due to Veenhoven (1991), is that more income improves happiness only until basic needs are met; beyond the point where there is enough income so that people are no longer hungry, their children do not die from readily preventable diseases, and absolute poverty has been eliminated, additional gains in income no longer matter for happiness. While this story seems plausible, there is a contrary view that it is only after these basic needs have been met that the possibilities for intellectual and cultural development can be fully explored. This belief is akin to Robbins' (1938) account of the Brahmin who claimed to be "ten times as capable of happiness as that untouchable over there." In fact, although the United States and Japan may have failed to become happier as they grew richer, low-income countries, such as India or Nigeria, are less happy than high-income countries (for example, Ingelhart and Klingemann, 2000; Graham, 2005; Layard, 2005; Leigh and Wolfers, 2006, or the careful and balanced survey by Diener and Oishi, 2000). However, controversy continues over whether, among the high-income countries, additional income brings additional life satisfaction.

The main source of previous empirical evidence on life satisfaction in countries around the world is the World Values Survey, which is conducted by a network of academics around the world who coordinate their efforts. Interviews have been carried out with samples of people of more than 80 countries, which together include over 85 percent of the world's population. The coverage includes the high-income countries of the world, together with a smaller number of low-income countries, as well as a group of countries from Eastern Europe and the former Soviet Union. The World Values Survey has been carried out in four waves: 1981, 1990-1991, 1995-1996 and 1999-2001. Data for the World Values Survey is available from a variety of sources, including the Interuniversity Consortium for Political and Social Research (ICPSR) survey data archive available on-line at the University of Michigan. For details on the World 
Values Survey, see <http://www.worldvaluessurvey.org>. Several of the studies based on the World Values Survey data have concluded that high-income countries are happier, but that among the high-income countries, there is no relationship between national income and national happiness (for example, Ingelhart and Klingemann, 2000, Figure 7.2; Layard (2005, p. 32) who writes that for "the Western industrial countries, the richer ones are no happier than the poorer."

In 2006, the Gallup Organization ran a World Poll using samples of people in each of 132 countries; with the exception of Angola, Cuba, and Myanmar, where the samples are urban, the samples are nationally representative of people aged 15 and older. The questionnaire covered many aspects of well-being, including an overall measure of life satisfaction, as well as several aspects of health and economic status. Because the survey used the same questionnaire in all countries, it provides an opportunity to make cross-country comparisons. No previous poll has provided national samples of so many countries, particularly poor countries. For details on the Gallup World Poll, see <http://www.gallupworldpoll.com/content/24046/About.aspx>. Here I focus on the life satisfaction question about life at the present time, measured on an eleven point scale from 0 ("the worst possible life") to 10 ("the best possible life"), and the health satisfaction question ("are you satisfied or dissatisfied with your personal health?"). I look at how the answers to these questions vary with age and with the objective circumstances of the country, particularly the levels and rates of change of per capita income and life expectancy.

"Life satisfaction" and "happiness" are not synonyms. Questions about life satisfaction ask respondents to make an overall evaluation of their lives. The results are often interpreted as measures of happiness, but happiness can also be thought of as relating to affect, and can be measured from experiential questions, for example, about smiling a lot, or feeling happy, or absence of depression, often during the day before the interview. The World Poll also includes such questions, and experiential happiness measures based upon them do not always line up with the evaluative measures from the life satisfaction question.

The analysis of the Gallup World Poll in this paper confirms a number of earlier findings, and also yields some new and different results. For example, high-income countries have greater life-satisfaction than low-income countries, and when income is measured in logarithmic terms, there is no evidence that the cross-country effects of greater income fade out or vanish as countries increase their income. Conditional on the level of national per capita income, the effects of economic growth are negative and not positive, as would be predicted by previous discussion and previous micro-based empirical evidence. Neither life satisfaction nor health satisfaction responds strongly to objective measures of health, such as life expectancy or the prevalence of HIV infection, so that neither provides a reliable indicator of population wellbeing over all domains, or even over health.

\section{Life Satisfaction and Income: Evidence From the World Poll}

\section{Per Capita Income and Life Satisfaction}

A global map of average life satisfaction levels by country based on the Gallup World Poll data looks much the same as an income map of the world: the inhabitants of North America, Western Europe, Japan, Australasia, and Saudi Arabia are both rich and well-satsfied with their lives, with average national life-satisfaction scores in the range of 7.5-8.5. The really unsatisfied places on the planet, with life-satisfaction scores in the range of 3.1-4.5, are in subSaharan Africa, plus Haiti and Cambodia. The only countries in the bottom 20 according to life-satisfaction and that are relatively well-off in income terms are Georgia and Armenia, though it is possible that the income levels in both are greatly overstated, an issue to which I 
shall return. At the other end, there are two relatively poor places in the life-satisfaction top 20: Costa Rica and Venezuela.

Figure 1 summarizes information about the relationship between life satisfaction and national income. The horizontal axis is per capita GDP in 2003 (the nearest year for which there is complete data in the Penn World Table) measured in purchasing power parity dollars at 2000 prices. Each circle is a country, with diameter proportional to population, and marks average life satisfaction and GDP for that country. Important countries are labeled; most of the countries of sub-Saharan Africa are on the bottom left, India and China are the two large circles near the left, the western European countries appear near the upper right, and the United States is the large country on the top right.

Figure 1 shows that life-satisfaction is higher in countries with higher GDP per head. The slope is steepest among the poorest countries, where income gains are associated with the largest increases in life-satisfaction, but it remains positive and substantial even among the rich countries; it is not true that there is some critical level of GDP per capita above which income has no further effect on life-satisfaction. Indeed, if we plot average happiness against the logarithm of per capita income, as in Figure 2, the relationship between per capita income and life satisfaction is close to linear. This is shown by the heavy broken line in the figure, which plots average life satisfaction for each level of GDP per capita. (I shall return to the other two lines below.) This line is somewhat steeper to the right of the figure, among the richer countries; the Brahmin theory does better than the story about basic needs. The log scale in Figure 2 also makes it easier to see the countries with the lowest levels of life-satisfaction, which include, in addition to countries in sub-Saharan Africa, Afghanistan, Cambodia, and Iraq.

Column 1 of Table 1 shows a regression for the 123 countries for which we have both lifesatisfaction and per capita PPP GDP from the Penn World Table. With income expressed as a $\log$, the relationship is close to linear: the coefficient is 0.859 , with a small standard error. Does this overall correlation hide a different pattern for the low-income and high-income countries? A quadratic term in the log of income (not shown) has a positive coefficient, confirming the impression in Figure 2 that the slope is higher among the richer countries. Another way to see this is to split the sample at $\$ 12,000$, which is a level that separates the poor and middle-income countries from the rich countries (as shown in Figure 1 and Figure 2). Columns 2 and 3 show that with per capita income measured in log terms, the slope in the upper income countries is higher, although it has a large estimated standard error. If we restrict the sample to the 25 countries whose per capita GDP is above $\$ 20,000$, shown in column 4, the estimated slope falls to 0.384 , but with so few countries the standard error is 0.782 , which is consistent both with true slope of zero slope, and also with a slope that is the same or higher than the lowincome countries; Figure 2 shows that the former is the natural conclusion. These results support a finding that the relationship between the log of income and life satisfaction offers a reasonable fit for all countries, whether high-income or low-income, and if there is any evidence for deviation, it is small and probably in the direction of the slope being higher among the highincome countries.

Why are these results so different from those studies that have concluded that, among the rich countries, national income has no effect on national life satisfaction? Figure 3 shows the World Poll data together with the data on which the earlier findings were based, taken from the three first waves of the World Values Surveys. For comparability with the World Poll, I have included only countries that appear in both sources, and I have excluded regions or cities. The hollow circles show the World Poll data and are the same as those in Figure 1; the shaded circles are the data from the World Values Survey (which are on a ten point rather than eleven point scale). When the latter has multiple observations on the same countries, I have used only the latest. Figure 3 shows that the data from the World Values Survey are broadly similar to 
those from the World Poll, but also that there are important differences. In both surveys, there is a positive relationship between life satisfaction and GDP per head, and the relationship is steeper among the poor countries than among the rich. However, Figure 3 also shows that while the World Poll data show a smooth relationship between life satisfaction and income, with a slope that falls gradually as we move to the richer countries, the data from the World Values Surveys presents an impression of a much steeper, almost vertical, slope among the poor countries, and apparently little increase in life satisfaction above about $\$ 10,000$ per capita.

What accounts for this difference in the pattern? There are several factors. First, the World Values Surveys includes very few of the poorest countries in the world, many of which are included in the World Poll, and which can be seen in the bottom left of Figure 3. If Figure 3 were to be redrawn with a log scale for income, as in Figure 2, most of the countries that help establish the bottom left of the close-to straight line in Figure 2 are missing from the World Values Survey. Second, a substantial number of the poorest countries in the World Values Survey are in Eastern Europe or were once part of the Soviet Union, including Moldova, Ukraine, Armenia, Belarus, Russia, Bulgaria, Latvia, Estonia, Azerbaijan, Bosnia and Herzegovina, Macedonia, Romania, Estonia, and Slovakia. People in those countries are exceptionally dissatisfied with their lives, and much more so in the earlier World Values Surveys than in the 2006 World Poll. And because they are not among the global poorest, at least according to the standard GDP measures, they establish a cluster of countries that lies well below the relationship between life satisfaction and income that holds in the World Poll.

Third, the World Values Survey, especially in its earlier rounds, sampled mostly literate and urban people in countries such as India, China, Ghana, and Nigeria, who were purposely selected to be more comparable with people in richer countries. Given the general relationship between life satisfaction and income, these people are almost certainly more satisfied with their lives than the typical inhabitant of their countries, and they establish another cluster of relatively poor countries, but now with high life satisfaction. The poor countries in the World Values Survey are therefore a mixture of unusually dissatisfied people from Eastern Europe and the former Soviet Union and unusually satisfied people from a small group of poorer countries. As a result the shaded circles in Figure 3 show close to no relationship between life satisfaction and income among the poor countries which, given the presence of the group of richer and more satisfied countries, creates the impression of a vertical relationship capped by a flat one. Yet when Figure 3 is drawn on a $\log$ scale to mimic Figure 2, the positive relationship between life satisfaction and GDP per head remains clear, even among the rich countries, though the scatter around the line is much greater.

In summary, there is nothing in the data from the World Values Survey that casts doubt on the World Poll data, nor on the close to linear global relationship between average life satisfaction and GDP per head. A similar point is also made by Leigh and Wolfers (2006).

\section{Growth of Income, Life Expectancy, and Life Satisfaction}

In looking at these correlations between income and life satisfaction, it is of course possible that income is standing in for something else, such as relative income, income relative to expectations or to past income (that is, economic growth), or for other variables correlated with income, of which some aspect of health is plausibly the most important. Indeed, the international pattern of life-satisfaction in relation to per capita GDP is very similar to the pattern between life-expectancy and income that was first documented by Preston (1975).

Table 2 investigates the economic growth and health stories. Column 1 regresses average life satisfaction on the logarithm of income in 2003 and the average growth rate of income from 2000 to 2003. (Note that this is mechanically equivalent to regressing life satisfaction on the logarithms of income in both 2000 and 2003, or indeed to regressing life satisfaction on the 
logarithm of income in 2000 and its growth from 2000 to 2003.) The addition of growth to the regression does not eliminate the effect of income in levels. Second, and more surprisingly, at any given level of income, economic growth is associated with lower reported levels of lifesatisfaction, a result that seems inconsistent with almost all of the accounts in the literature. One exception is Diener, Diener, and Diener (1995) who also find a negative effect of growth on happiness in an international sample of college students, though not in their national samples. However, this finding is one of the most surprising results in this paper.

Note that growth from 2000 to 2003 is the total change in log income over these three years, so that the regression in column 1 can also be interpreted as a levels regression in which log income in 2003 attracts a negative coefficient, and log income in 2000 a positive one, with their sum remaining at 0.860 . Essentially these data cannot tell which year's income is the most important one, a finding that is confirmed by adding further lags of log income (not shown). Yet in all of these alternative specifications, the sum of the coefficients on the lags remains roughly constant, which is consistent with life-satisfaction responding to the long-term average income, as in a permanent-income model of life satisfaction. Column (2) also shows that the precise period of income growth is not important, and that the model does just as well assigning the negative effects of growth to the three years from 2000 to 2003, or the decade from 1990 to 2000 , or some combination of the two. The addition of earlier growth rates does nothing to enhance or change these results.

The coefficients on growth, even when divided by three, are larger in absolute value than the coefficient on the current level of income. This pattern implies that a regression with lifesatisfaction as the dependent variable and lagged income and current growth as the explanatory variables will still show a negative effect of growth; the coefficient on lagged income is the same as that on current income in the original regression. This finding rules out the possibility that the negative effect of growth comes from identifying those countries whose current income overstates their long-run income, and who should therefore be less happy than those who have been richer for longer. However we count it, income makes countries more satisfied with their lives and income growth makes them less satsified.

The countries of Eastern Europe and of the former Soviet Union have some of the lowest levels of life-satisfaction in the world, much lower than is warranted by their measured incomes. They also have amongst the most unreliable estimates of incomes in international dollars.

International comparisons of GDP, as in the Penn World Table, start with comparisons of groups of countries, which are then linked together using a system of "bridge" countries that belong to more than one group. Because the countries of the former Soviet Union were incorporated into the global system as a block, their estimates of PPP exchange rates are subject to common errors, so that all of their incomes are likely overstated or understated together. Given that all of them have such low life satisfaction relative to their per capita incomes, there must be a suspicion that their incomes are overstated by the estimates by the Penn World Table and the World Bank. These countries were also among the fastest growing from 2000 to 2003; Twelve of the 20 fastest growing economies are in this group, as are three of the top five, Kazakhstan (1), Armenia (2), and Ukraine (4). Their low levels of life satisfaction contribute to the negative relationship between life satisfaction and growth in Table 2; excluding them does not remove the negative effect, but it reduces it to insignificance.

Columns 3, 4, and 5 investigate the role of life expectancy and its change. Life expectancy is estimated based on the then-current survival rates in 1990 and in 2000; measured in this way, life expectancy is not a long-term measure that changes only slowly in response to changes in the epidemiological and social environment. In this sample, 21 countries saw life expectancies fell from 1990 to 2005. Thirteen of these are in sub-Saharan Africa-as are all of the doubledigit declines - two are in the Caribbean, and the other six are countries of the former Soviet 
Union, including Russia itself. (Estimates of life-expectancy are available for these countries in 1990, although income estimates are not.) Yet life-expectancy plays a very limited role in explaining international variations in life satisfaction. The introduction of the life-expectancy variables has only a small effect on the estimated effects of income, so that apparently income is not just serving as a proxy for life-expectancy. In fact, life-expectancy itself does not show up significantly in any of the regressions, though the increase in life-expectancy from 1990 to 2005 has a significant positive effect on average life-satisfaction. The estimated coefficient is 0.044 , which would exert a sizeable negative effect on life-satisfaction in countries in sub-

Saharan Africa with large declines in life expectancy, such as Botswana (-29 years), Zimbabwe ( -21 years) or South Africa ( -14 years), but cannot explain the low levels of life satisfaction in the countries of the former Soviet Union where the declines were much smaller, such as Russia ( -3 years).

I have repeated the life satisfaction regressions using infant and child mortality measures instead of, and in addition to, life expectancy; these are arguably better measures of the extent to which basic needs are fulfilled. But these other calculations generate no new insights, largely because of the strong interrelations between the three measures in a single cross-section. Indeed, in the poorest and highest mortality countries, amongst whom the variation in life expectancy is largest, life expectancy is often imputed using measures of infant and child mortality, so it is not surprising that the data should be unable to separate their effects, if indeed they exist. I have also experimented with a measure of the HIV prevalence rate (taken from the World Development Indicators of the World Bank). Because this rate is surely measured with error, as well as relying on the specific numbers, I constructed a dummy variable that identifies the 13 countries with an estimated 2003 prevalence of 5 percent or more: Botswana, Burundi, Cameroon, Haiti, Kenya, Mozambique, Malawi, Nigeria, Rwanda, South Africa, Tanzania, Zambia, and Zimbabwe. Whether added to the regressions in column (1) or column (3) of Table 2, neither the dummy nor the prevalence estimate attracts a statistically or economically significant coefficient (not shown). It seems astonishing that reported life satisfaction should be unaffected by a plague whose severity is unparalleled in modern times. Even if people do not know that they are HIV-positive, it is hard to believe that their lifesatisfaction is unaffected when more than a fifth of adults are infected, and when burials of the victims are a daily occurrence.

\section{Life satisfaction, age, and GDP}

Figure 2 shows the global relationship of life satisfaction and per capita GDP on a log scale. It also contains three lines. The middle line shows average life satisfaction for each level of per capita GDP while the outer two lines show the same thing, but for two age groups, ages 15 to 25-the upper line for most of the figure - and ages 60 and over - which is usually the lower line. For most of the world, life satisfaction declines with age; the exception being the very richest countries - including the US, Canada, UK, Australia and New Zealand, where life satisfaction is U-shaped with age, falling at first and rising after middle age. For example, in the United States average life satisfactions scores go from about 7.8 at 20, fall to about 6.8 by the late $30 \mathrm{~s}$, and then rise back to about 7.8 by the early $60 \mathrm{~s}$.

The decline of life-satisfaction with age is largest among the middle-income countries in Figure 2, and is particularly marked among the countries of Eastern Europe and the former Soviet Union where there is an almost uniform pattern of life-satisfaction declining with age, often quite sharply. In Russia, for example, the average life satisfaction score for 15 to 19 year-olds is 5.99, while the average life satisfaction score for those aged 65 and over is 4.3; in Hungary, the corresponding figures are 7 and 4.95. (These patterns are unconditional averages of lifesatisfaction with age, with no adjustments for cohorts or othercovariates.) Whatever aspects of the economic transition is making the citizens of these countries dissatisfied with their lives, 
the effects are much more pronounced among the elderly. Perhaps it is they who have suffered the adverse consequences of disruption, who were most satisfied with their old lives, and who cannot expect to live long enough to see any improvements that might occur in the future.

There is one other notable feature of Figure 2. In the low income countries, the decline in life satisfaction with age is relatively small; in the middle income countries, it is larger, and then diminishes with GDP per capita until there is a reversal amond the rich. At least in 2006, and in countries with per capita GDP of more than $\$ 2,000$, living in a higher income country appears to protect people against the effects of age on life-satisfaction.

I have replicated the income results in Table 1 and Table 2 by age group, and the results are qualitatively similar to those for all age groups combined. For each of the age groups, the level of national income is an important positive determinant of life-satisfaction, and the rate of growth of income a negative determinant. In further work, when the individual income numbers from the World Poll are more developed, it may be possible to use the data to look at income distribution across age groups, or to compare the effects of income on happiness within each country with those estimated here from the international comparisons.

\section{Health Satisfaction and Health Systems}

I now turn from overall life-satisfaction to satisfaction with health. Gallup World Poll respondents are asked whether or not they are satisfied or dissatisfied with the state of their personal health.

Figure 4 shows the global relationship between the fraction of people who are satisfied with their health, age, and GDP per capita. Countries are plotted as circles with diameters proportional to population; these show the fraction of people satisfied with their health in the population as a whole. Variation of health satisfaction with age is plotted as a series of fitted nonparametric regression curves that show average health satisfaction against GDP per capita for seven different age groups; I am assuming that the GDP per capita figure is a suitable indicator for all age groups in each country. The figure shows that people are more likely to be satisfied with their health in high income countries, and that they become less satisfied with their health as they age; as we might expect for health, the effects of age are much larger than the effects of national income. Remarkably, the rate at which health satisfaction deteriorates with age is greater in low-and middle-income countries than in high-income countries, where income seems to provide some protection against the effects of aging on self-perceived health. At the top right of Figure 4, the 50-59 age group is actually less satisfied with its health than is either of the two older groups, and this pattern can be confirmed in individual rich countries such as the US. It is most improbable that this reversal can be attributed to any objective health conditions or disabilities. Perhaps the 50-59 group is particularly intolerant of the first signs of aging

In health satisfaction, as in life satisfaction, the countries of Eastern Europe and the former Soviet Union report extraordinary low levels - in fact, these countries represent 11 of the 20 lowest countries in the world in health satisfaction, including Ukraine (rank 1), Russia (3), Georgia (4), Armenia (5), Belarus (6), Moldova (8), Hungary (9), Latvia (12), Estonia (13), Romania (15), Kazakhstan (17), and Bulgaria (19). More understandably, other low-ranking countries in health satisfaction include such high mortality countries such as Haiti (2), Rwanda (7), Uganda (10), Burundi (11), Cambodia (14), Chad (16), Benin (18), and Cameroon (20). (South Korea ranks $21^{\text {st }}$ for no immediately obvious reason.) In all of these countries, the fraction of people reporting themselves satisfied with their health is between a half and twothirds, which is worth contrasting with the situation in some of countries worst-hit by the HIV/ AIDS epidemic, Tanzania (71 percent), Zimbabwe (75 percent), Botswana and South Africa (both 78 percent), and Kenya ( 82 percent). Indeed, the percentage of Kenyans satisfied with 
their health is the same as the proportion of Britons, and is a percentage point higher than the fraction of Americans though at least some of this comes from the younger average age of the Kenyan respondents. If we age-adjust to the British population, the fraction of Kenyans satisfied with their health is ten points lower than in Britain or the US. Even so, it appears that the declines in life expectancy in the countries of the former Soviet Union have had a much larger effect on reported life satisfaction than have the much larger declines in life expectancy in the African countries affected by HIV/AIDS.

We can also examine the way that health satisfaction declines with age and how that decline varies internationally. In the 15-19 age group, almost everyone is satisfied with their health. In the rich countries, satisfaction falls relatively slowly, and in the United States, actually improves with age after age 50-probably coincidentally overtaking the generally more stoical British at around the age at which the respective age-specific mortality curves cross. In the Eastern European and former Soviet Union group, health satisfaction falls very rapidly with age, and very large fractions of the elderly report themselves as dissatisfied with their health.

Table 3 explores the correlates of health satisfaction, following the same general procedures as in Table 2, regressing average health on a set of possible covariates. Because age is a much more important determinant of health satisfaction than of life satisfaction, all of these regressions control for the age structure of the population. Column 1 shows, consistently with the figure, that the fraction of people satisfied with their health is higher in higher income countries although, even allowing for the fact that the scale is a tenth as large, the effect is a good deal smaller than for life-satisfaction. As was the case for life satisfaction, recent economic growth is negatively associated with health satisfaction conditional on the level of GDP per capita; once again, the countries of Eastern Europe and the former Soviet Union drive much of this result. In column 2, neither the level of life expectancy nor its increase from 1990 to 2005 have any effect on health satisfaction. This lack of a link between reported health satisfaction and at least these objective measures of health is disturbing, so I investigate it further. Declines in life expectancy are associated either with HIV/AIDS (itself mostly in subSaharan Africa), or with the transition countries of Eastern Europe, so I constructed three dummy variables, one for the Eastern European countries, one for sub-Saharan Africa, and one the dummy for HIV prevalence that has already been described. The first of these dummies ("east") attracts a negative and significant coefficient, the second (sub-Saharan Africa) an insignificantly negative one, and the third (HIV) a coefficient that is neither negative nor significant. This result is perhaps not surprising given the evidence in Figure 4, where it is clear that the poor health satisfaction in the transition countries could not be attributed entirely to the objective decrease in life expectancy. These results also reinforce the fact that even high levels of HIV prevalence do not much affect the health satisfaction reports-or at least not in proportion to their dire effects on mortality. I have also interacted the dummies with the change in life expectancy (results not shown) to test the possibility that the changes in life expectancy have different effects in the different areas, or with different causes, but the estimated effects are neither significant nor informative.

One variable which is correlated with average health satisfaction is what people think of their health care system. The Gallup World Poll asks people to report whether or not they have confidence in their health care or medical system. The average level of confidence for each country is entered in the last row of the last column of Table 3, where it has a positive and statistically significant coefficient. Of course, because this response is itself subjective, we do not know whether it is a useful indicator of the actual performance of the health care system. Put differently, both health satisfaction and healthcare confidence may be functions of third factors which themselves vary by region, time, or age group. It would certainly be unwarranted to interpret the last column of the table as evidence that health care systems are effective in delivering health. 
The degree of confidence in the health care system varies widely from country to country, as shown in Figure 5, and although it is correlated with income, the correlation is weak. Almost all the inhabitants of high income countries are well-satisfied with their health care and medical systems; that the United States is an exception in this regard is well-known. Davis et al. (2007) find that while the United States does not lag in the effectiveness of healthcare, but does so in other dimensions such as equity, access, and safety. Experience is much more diverse among the low-income countries of the world, but people in some low-income countries such as Vietnam, Thailand, Malaysia, and Cuba have great confidence in their health care and medical system, and the majority of those in low-income countries show greater public confidence than does the United States, even though the people of those countries experience much worse health outcomes. The ranking of the United States in the World Poll (88 out of 120 nations, five of which do not have income data and so do not appear in Figure 5) is even worse than in WHO (2000), which ranked it $37^{\text {th }}$ out of 191 (the WHO ranked Sierra Leone $191^{\text {st }}$ which is only three places behind the US in the World Poll), though it should also be noted that the WHO's methodology has been effectively challenged by several commentators, see particularly Williams (2001).

Given the high correlation between subjective evaluations in different domains-here between satisfaction with personal health and with the health care system-it is worth returning to life satisfaction and asking whether we can "explain" life satisfaction in terms of health satisfaction. This inquiry follows Easterlin (2006), who relates overall life satisfaction to satisfactions in the various domains and thus aggregating satisfactions into an overall evaluation. If we repeat the regressions in Table 2 with health satisfaction as an additional explanatory variable, the health satisfaction variable has a large (close to 4 ) and statistically significant coefficient. Moreover, with this variable added, the coefficients on life expectancy, the change in life expectancy, and the rate of economic growth lose their significance. While such regressions are useful for understanding the life satisfaction responses (though one might just as well argue for regressing health satisfaction on life satisfaction), they are less useful for deciphering the relationship between the satisfaction reports and the objective circumstances of life.

\section{Discussion}

Without health, there is very little that people can do and, without income, health alone does little to enable people to lead a good life. Other factors, such as education, or the ability to participate in society, are important too, although income and health tend to get the primary attention in most evaluations of human wellbeing. For many reasons, elaborated by Sen and others, self-reports of satisfaction with life, with income, or health are given little weight. People may adapt to misery and hardship, and cease to see it for what it is. People do not necessarily perceive the constraints caused by their lack of freedom; the child who is potentially a great musician, but never has a chance to find out, will not express her lack of life satisfaction. Whole groups can be taught that their poor health, or their lack of political participation, are natural or even desirable aspects of a good world.

In spite of these arguments, reports of life satisfaction, at least on average, may provide a useful summary of the different components of peoples' capabilities. Some of the results in this paper support that position, more so than I had originally expected. In particular, the very strong global relationship between per capita GDP and life satisfaction suggests that, on average, people have a good idea of how income, or the lack of it, affects their lives. It is not true that the people of India are as satisfied with their lives as the people of France, let alone Denmark; nor is it true that people in sub-Saharan Africa, or Afghanistan, or Iraq, or Cambodia, are as satisfied as people in India. Beyond that, the misery of many of the countries of Eastern Europe and the former Soviet Union seems plausible enough, as does the special misery of the elderly in those countries. 
It is far from clear why questions of life satisfaction should be so closely related to national incomes. A good deal of the literature emphasizes the relative nature of such responses; when people answer such questions, they must surely assess their life satisfaction relative to some benchmark, such as their own life in the past, or the lives of those around them. Indeed, in their recent review, Clark, Frijters, and Shields (2007), argue that life satisfaction is sensitive to respondent's income relative to those with whom they most closely associate, which implies that there should be no relation between average national life satisfaction and national income, unless there is some other aspect of national income that raises everyone's life satisfaction together. A simpler interpretation of the World Poll findings is that, when asked to imagine the best and worst possible lives for themselves, points 10 and 0 on the scale, they use a global standard. Danes understand how bad life is in Togo and other poor places, and the Togolese, through television and newspapers, understand how good life is in Denmark or other rich countries. If this is correct, the high correlation is a consequence of the globalization of information, and could not have existed in its absence. Such an interpretation is also consistent with the Easterlin paradox. The "best possible life for you" is a shifting standard that will move upwards with rising living standards, so that we might expect the Danes to continue to report eight out of ten as national income rises, provided they stay in the same position in the global income rankings. Indeed, it is hard to see how they could do differently faced with a scale that has a maximum of ten. According to this view, average national life satisfaction will be a useful measure in the cross-section, but not over time.

When we turn to health and its effects on life-satisfaction, the poll results diverge from what would be required in a "capabilities approach" to an understanding of the sources of human well-being. Longer life expectancy surely enables people to do more with their lives, and is arguably the best single indicator of population health. Yet, conditional on income, longer life expectancy has no apparent effect on life satisfaction. Instead, it is changes in the expectation of life that seem to have an effect, no matter whether life expectancy is high or low. Even satisfaction with health, a more focused question, is not related to life expectancy. The extraordinary low health satisfaction ratings for Eastern Europe and the countries of the former Soviet Union are a testament, not to their poor population health, but to a decline in health among a population that was used to a better state of affairs. In the high-income countries, it is people in their $50 \mathrm{~s}$, not in their $60 \mathrm{~s}$ or $70 \mathrm{~s}$, who report the least satisfaction with their health. Clearly, the health of people in their 50s is better than that of their elders, but this is an age when people experience serious health problems for the first time; perhaps it is not poor health that is hard to bear, but the first intimations of mortality. In the low-income countries, and particularly in Africa, where the joint evolution of man and parasites has ensured that, for hundreds of thousands of years, morbidity has been a constant companion throughout life (Iliffe, 1995), health satisfaction declines rapidly with age. But this pattern does not make health satisfaction a good indicator of health capabilities in the poorest countries. After all, countries with high rates of HIV prevalence do not systematically report poorer health satisfaction, a finding that is in line with earlier reports that self-reported health measures are often better in places where people are sicker, and presumably more adapted to being sick (Sen, 2002; Chen and Murray, 1992).

In spite of the positive relationship between life satisfaction and national income, and in spite of the plausibility of unhappiness and health dissatisfaction in the countries of Eastern Europe, neither life satisfaction nor health satisfaction can be taken as reliable indicators of population well-being, if only because neither adequately reflects objective conditions of health.

Even if this conclusion is accepted — and for a somewhat different view see Graham (2005) the satisfaction questions are clearly of interest in their own right, as is the analysis of their correlates. The survey measures of life and health satisfaction are among the best measures 
that we have of one important aspect of human experience, and economists and other social scientists need to understand what and why they are.

\section{Acknowledgements}

I am grateful to the Gallup Organization for providing me access to the Gallup World Poll, and to Daron Acemoglu, Raksha Arora, Tim Besley, Yonas Biru, Anne Case, Richard Chiburis, Ed Diener, Carol Graham, John Helliwell, Alan Heston, Danny Kahneman, David Laibson, Richard Layard, Andrew Oswald, Glenn Phelps and Jim Smith for help, comments and suggestions. I acknowledge financial support from the National Institute on Aging through grants No. R01 AG20275-01 to Princeton and P01 AG05842-14 to the NBER. This is a shortened and rewritten version of the July 2007 Working Paper, "Income, aging, health and wellbeing around the world: evidence from the Gallup World Poll" which is available as NBER Working Paper No. 13317.

\section{References}

Blanchflower, DavidG; Oswald, Andrew. Welll-being over time in Britain and the USA. Journal of Public Economics 2004;88:1359-1386.

Chen, Lincoln; Murray, Christopher. Understanding morbidity change. Population and Development Review 1992;18:481-504.

Clark, AndrewE; Frijters, Paul; Shields, MichaelA. Relative income, happiness, and utility: an explanation for the Easterlin paradox and other puzzles. Journal of Economic Literature. 2007forthcoming

Davis, Karen; Schoen, Cathy; Schoenbaum, StephenC; Dory, MichelleM; Holmgren, AlyssaL; Kriss, JenniferL; Shea, KatherineK. New York: The Commonwealth Fund; 2007. Mirror, mirror on the wall: an international update on the comparative performance of American health care.

Diener, Ed; Diener, Marissa; Diener, Carol. Factors predicting the subjective well-being of nations. Journal of Personality and Social Psychology 1995;69(5):851-864. [PubMed: 7473035]

Diener, Ed; Oishi, Shigehiro. Money and happiness: income and subjective well-being across nations. In: Diener, Ed; Suh, EunkookM, editors. Culture and subjective well-being. Cambridge, MA: MIT Press; 2000. p. 185-218.

Di Tella, Rafael; Haisken-DeNew, John; MacCulloch, Robert. Happiness adaptation to income and to status in an individual panel. 2005processed October

Easterlin, RichardA. Does economic growth improve the human lot?. In: David, PaulA; Reder, MelvinW, editors. Nations and households in economic growth: essays in honor of Moses Abramovitz. New York: Academic Press; 1974. p. 89-125.

Easterlin, RichardA. Will raising the incomes of all increase the happiness of all? Journal of Economic Behavior and Organization 1995;27:35-48.

Easterlin, RichardA. Explaining happiness. Proceedings of the National Academy of Science 2003;100 (19):11176-11183.

Easterlin, RichardA. Life cycle happiness and its sources: intersections of psychology, economics and demography. Journal of Economic Psychology 2006;27:463-482.

Graham, Carol. Insights on development from the economics of happiness. World Bank Research Observer 2005:201-231.

Helliwell, JohnF. How's life? Combining individual and national variables to explain subjective wellbeing. Economic Modeling 2003;20:331-360.

Iliffe, John. Africans: the history of a continent. Cambridge: Cambridge University Press; 1995.

Inglehart, Ronald; Klingemann, Hand-Dieter. Genes, culture, democracy, and happiness. In: Diener, Ed; Suh, EunkookM, editors. Culture and subjective well-being. Cambridge, MA: MIT Press; 2000. p. 165-183.

Kahneman, Daniel; Krueger, AlanB; Schkade, David; Schwarz, Norbert; Stone, ArthurA. Would you be happier if you were richer? A focusing illusion. Science 2006;312:1908-1910. [PubMed: 16809528]

Layard, Richard. Happiness: lessons from a new science. New York: The Penguin Press; 2005.

Leigh, Andrew; Wolfers, Justin. Happiness and the human development index: Australia is not a paradox. The Australian Economic Review 2006;39(2):176-184. 
Preston, SamuelH. The changing relation between mortality and level of economic development. Population Studies 1975;29:231-248. [PubMed: 11630494]

Robbins, Lionel. Interpersonal comparisons of utility: a comment. Economic Journal 1938;48:635-641.

Sen, AmartyaK. Development as freedom. New York: Knopf; 1999.

Sen, AmartyaK. Health: perception versus observation. British Medical Journal 2002;324:860-861. [PubMed: 11950717]

Veenhoven, Ruut. Is happiness relative? Social Indicators Research 1991;24:1-34.

Williams, Alan. Science or marketing at WHO? A commentary on "World Health 2000. Health Economics 2001;10:93-100. [PubMed: 11252041]

World Health Organization. World Health Report 2000-Health systems, improving performance. Geneva: WHO; 


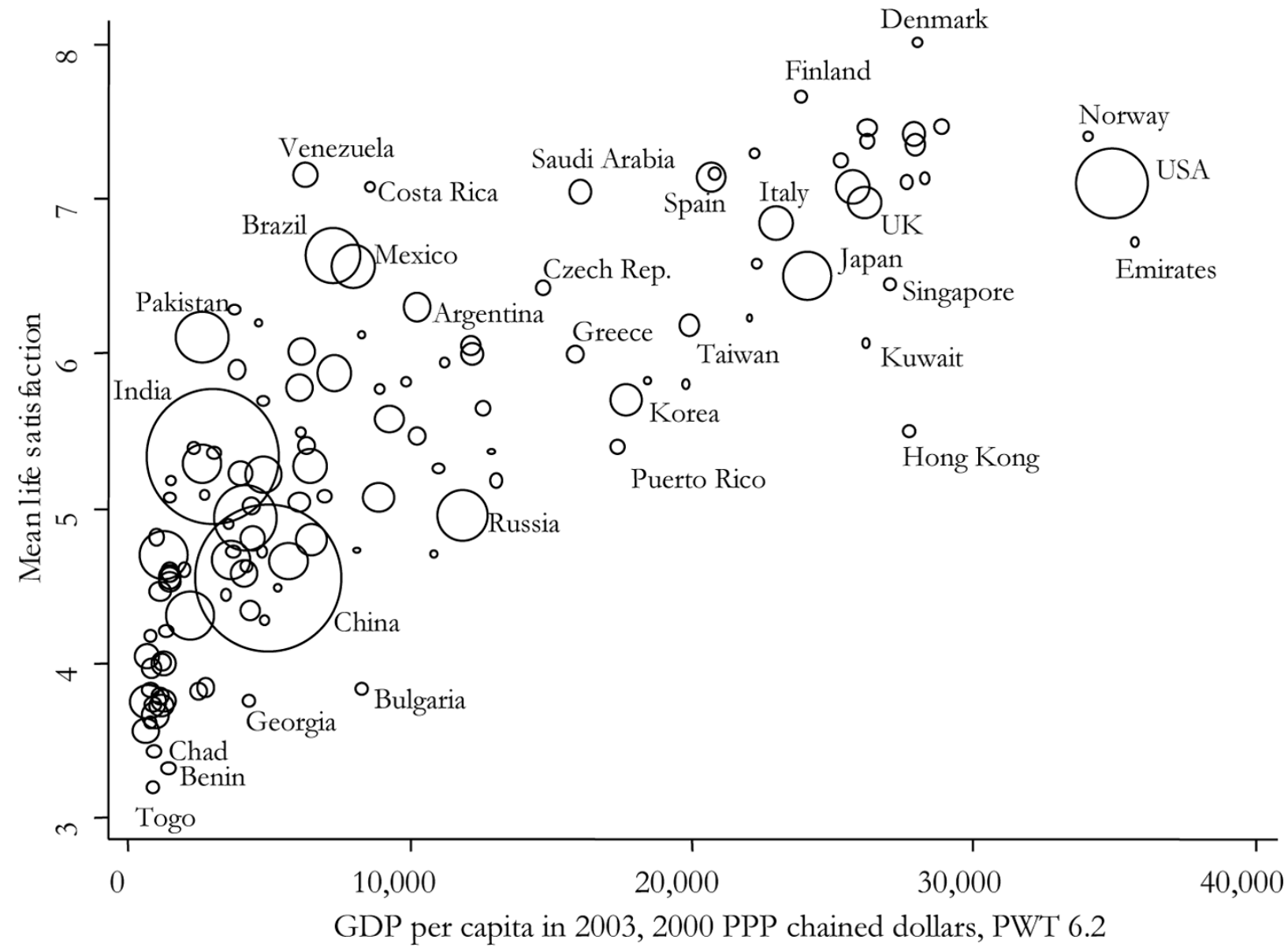

Figure 1.

Life satisfaction and per capita GDP around the world 


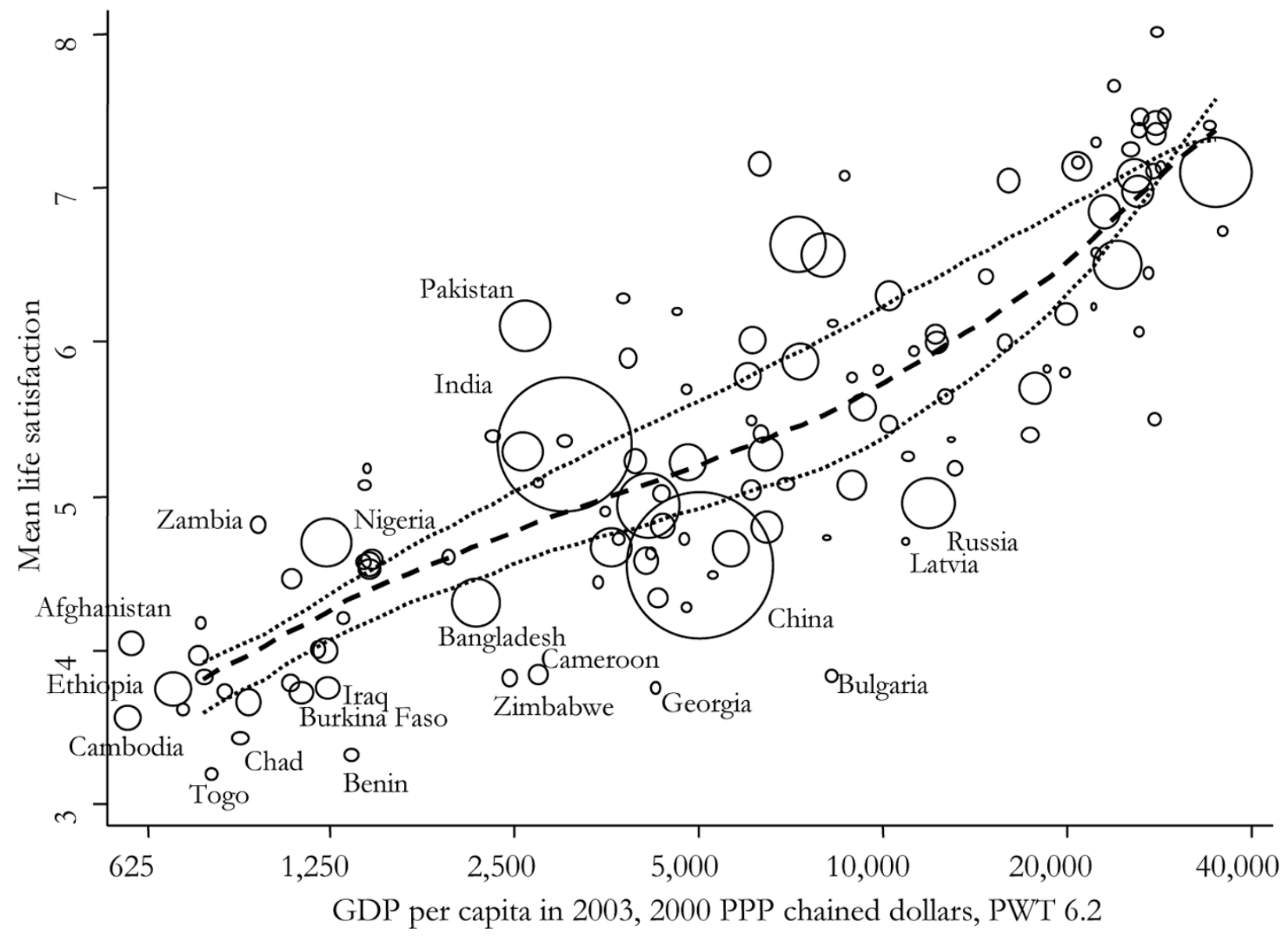

Figure 2.

Each doubling of GDP is associated with a constant increase in life satisfaction 


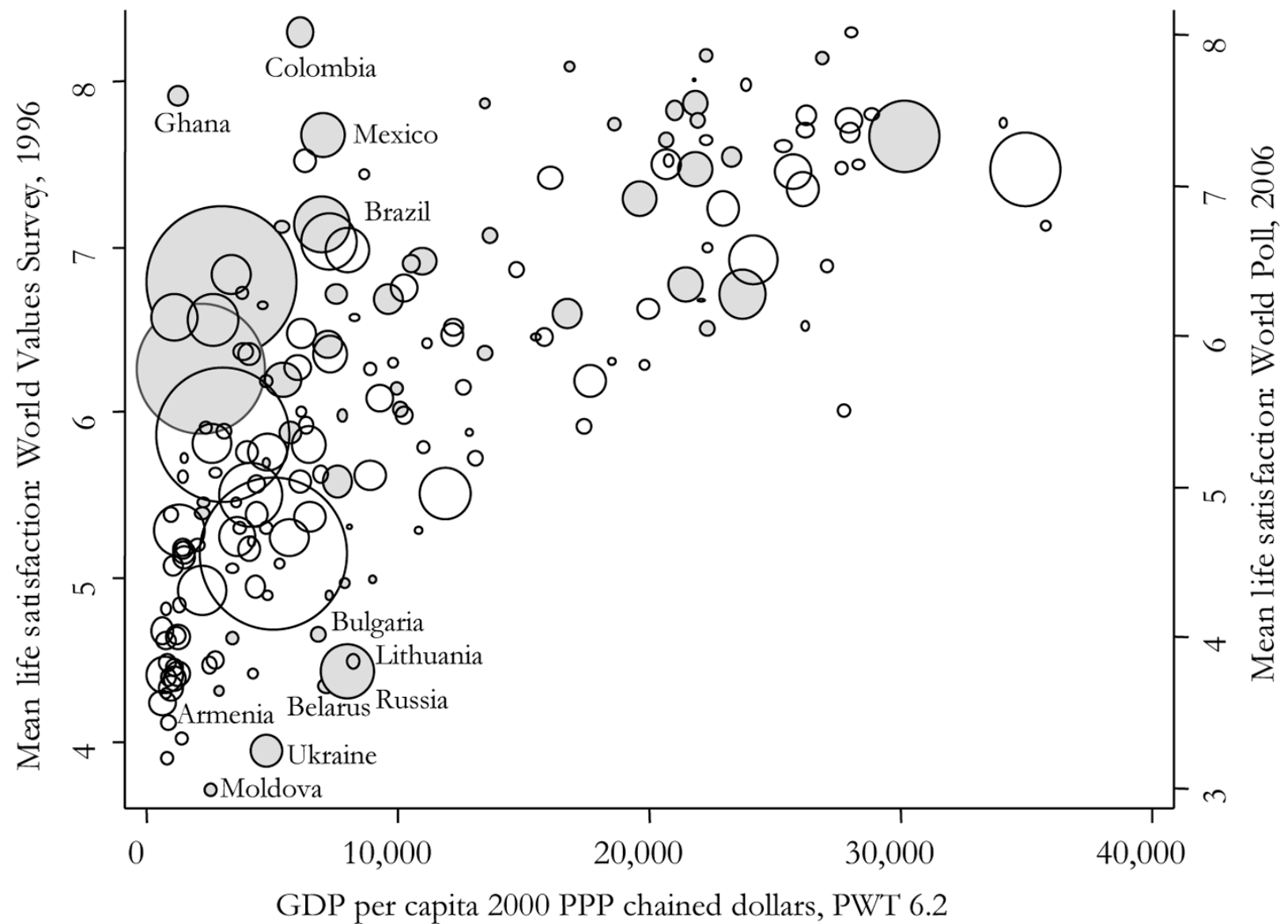

Figure 3.

Life satisfaction in the World Poll and the World Values Surveys (World Poll shown as hollow circles, World Values Surveys as shaded.) 


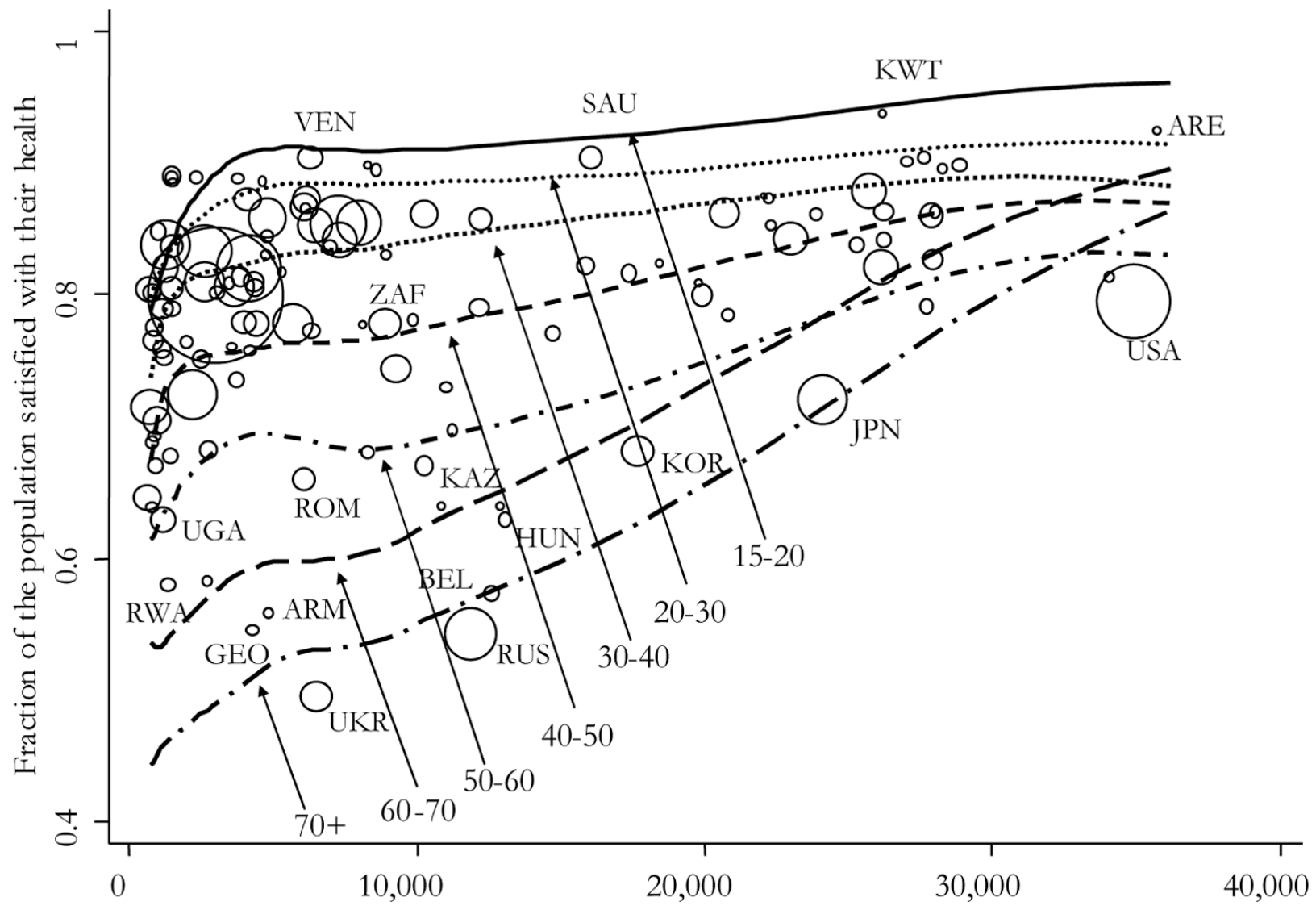

Per capita GDP in 2003, 2000 chained PPP dollars

Figure 4.

Health satisfaction, age, and per capita GDP 


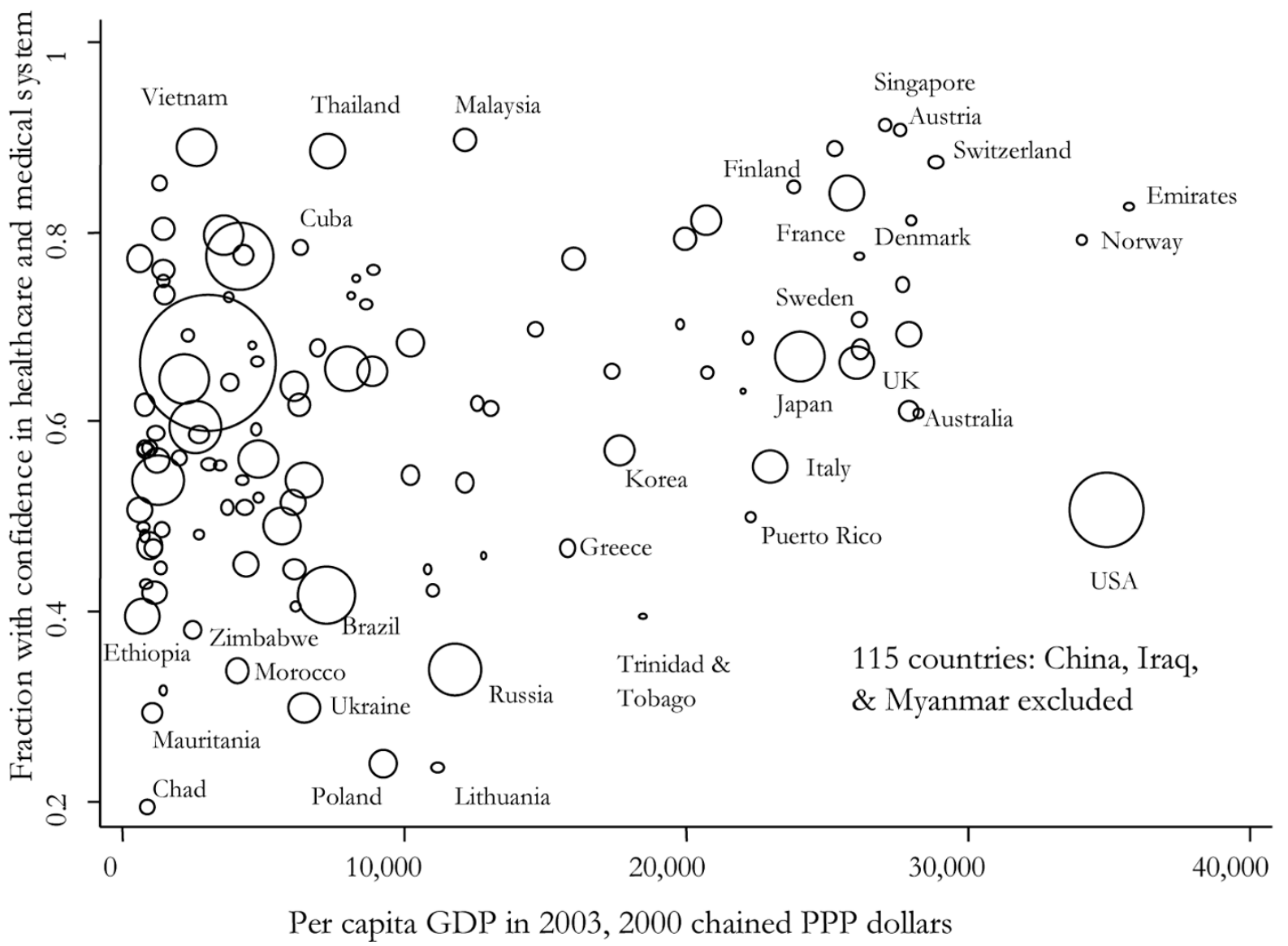

Figure 5.

Confidence in healthcare and medical systems around the world 
Table 1

Cross-country regressions of average life-satisfaction on the logarithm of per capita GDP

\begin{tabular}{lllll}
\hline & $(\mathbf{1})$ & $\mathbf{( 2 )}$ & $\mathbf{( 3 )}$ & $\mathbf{( 4 )}$ \\
\hline Income cutoff & None & $\mathbf{y}<\mathbf{1 2 , 0 0 0}$ & $\mathbf{y}>\mathbf{1 2 , 0 0 0}$ & $\mathbf{y}>\mathbf{2 0 . 0 0 0}$ \\
\hline $\ln y$ & 0.838 & 0.690 & 1.625 & $(0.312)$ \\
s.e. & $(0.051)$ & $(0.082)$ & $0.782)$ \\
\hline$R^{2}$ & 0.694 & 0.430 & 0.010 \\
Number of countries & 123 & 85 & 38 \\
\hline
\end{tabular}

Notes: $y$ is real chained GDP per capita in 2003 in 2000 international \$ from the Penn World Table version 6.2. Regressions are not weighted by population. 


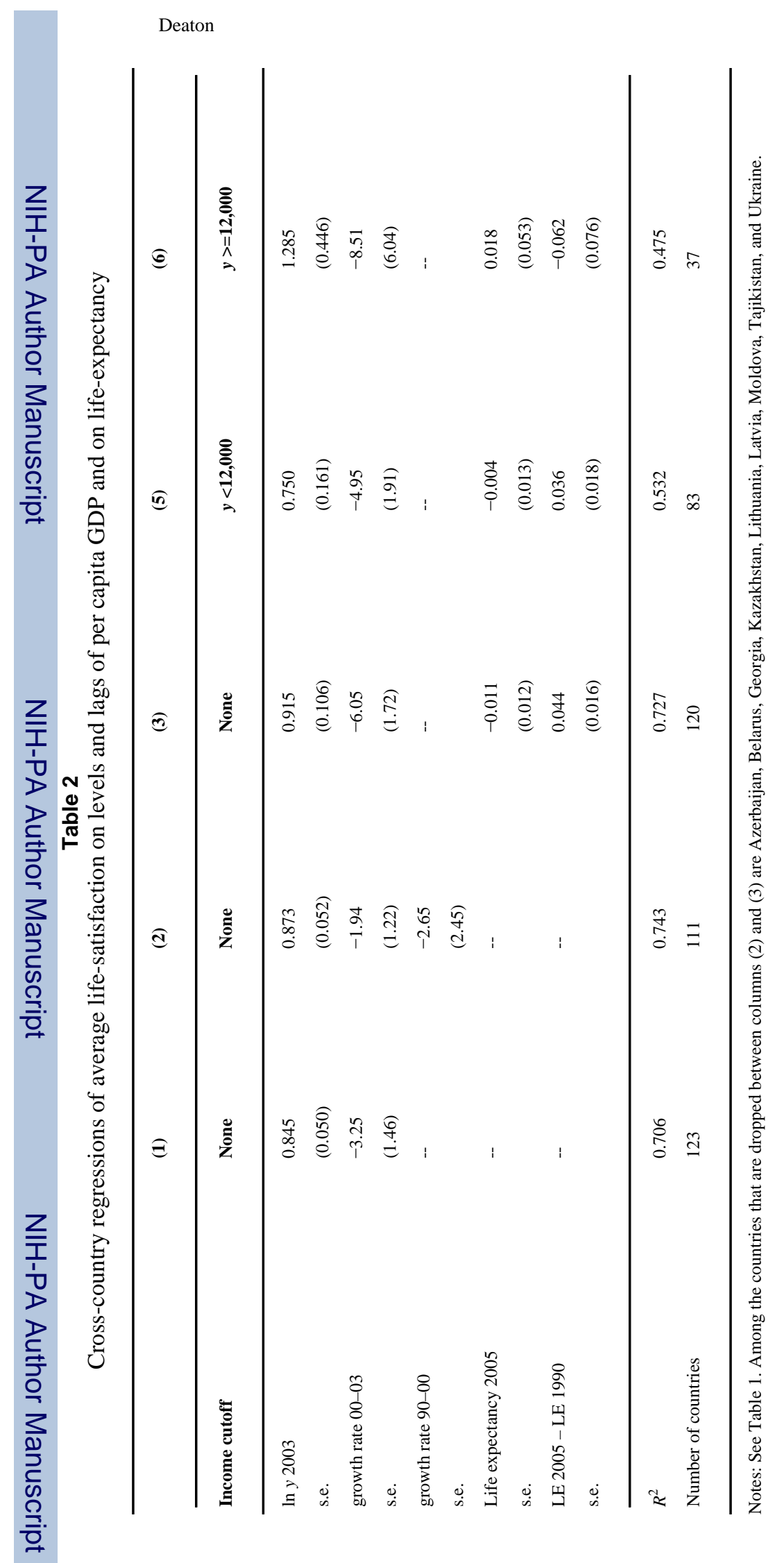

J Econ Perspect. Author manuscript; available in PMC 2009 May 11. 
Table 3

Cross-country regressions of average health-satisfaction

\begin{tabular}{|c|c|c|c|c|}
\hline & (1) & (2) & (3) & (5) \\
\hline $\ln y 2003$ & 0.0537 & 0.0561 & 0.0350 & 0.0323 \\
\hline s.e. & $(0.009)$ & $(0.013)$ & $(0.013)$ & $(0.014)$ \\
\hline growth rate $00-03$ & -1.176 & -1.234 & -0.687 & -0.665 \\
\hline s.e. & $(0.206)$ & $(0.209)$ & $(0.223)$ & $(0.231)$ \\
\hline Life expectancy 2005 & -- & 0.000 & 0.003 & 0.002 \\
\hline s.e. & & $(0.001)$ & $(0.002)$ & $(0.002)$ \\
\hline LE 2005 - LE 1990 & -- & 0.003 & 0.001 & 0.000 \\
\hline s.e. & & $(0.002)$ & $(0.002)$ & $(0.002)$ \\
\hline \multirow[t]{2}{*}{ east } & -- & -- & -0.102 & -0.098 \\
\hline & & & $(0.020)$ & $(0.023)$ \\
\hline \multirow[t]{2}{*}{ ssa } & -- & -- & -0.016 & -0.011 \\
\hline & & & $(0.035)$ & $(0.034)$ \\
\hline \multirow[t]{2}{*}{ hiv } & -- & -- & 0.039 & 0.022 \\
\hline & & & $(0.030)$ & $(0.031)$ \\
\hline \multirow{2}{*}{$\begin{array}{l}\text { confidence in } \\
\text { healthcare }\end{array}$} & -- & -- & -- & 0.087 \\
\hline & & & & $(0.043)$ \\
\hline$R^{2}$ & 0.463 & 0.511 & 0.621 & 0.645 \\
\hline Number of countries & 120 & 119 & 119 & 113 \\
\hline
\end{tabular}

Notes: East is a dummy that is one for Eastern Europe and the Former Soviet Union, SSA is a dummy that is one for sub-Saharan Africa, and hiv is a dummy that is one for countries where the estimated prevalence rate of HIV/AIDS in 2003 is greater than 5 percent. Each regression contains a set of age controls, the fractions of the population in (all but one of) the age groups 15-19, 20-29, 30-39, 40-49, 50-59, 60-69, and 70 plus. 